\title{
The Diversity of Providers on the Family Medicine Team
}

\author{
Andrew Bazemore, MD, MPH, Peter Wingrove, BS, Lars Peterson, MD, PhD, and \\ Stephen Petterson, $\mathrm{PhD}$
}

Family physicians are increasingly incorporating other health care providers into their practice teams to better meet the needs of increasingly complex and comorbid patients. While a majority of family physicians report working with a nurse practitioner, only $21 \%$ work with a behavioral health specialist. A better understanding of optimal team composition and function in primary care is essential to realizing the promise of a patient-centered medical home and achieving the triple aim. (J Am Board Fam Med 2016;29:8-9.)

Keywords: Behavioral Medicine, Career Choice, Family Practice, Health Policy, Patient-centered Care

Transforming primary care practices to better serve the nation's triple aim-improved patient experience, improved population health, and reduced costs-requires reorienting care delivery around teams of providers. ${ }^{1}$ Studies have shown that increasing percentages of family physicians work with nurse practitioners (NPs) and physician assistants $(\mathrm{PAs}),{ }^{2}$ but much less is known about the prevalence of other health care providers in primary care practice, the nation's largest health care delivery platform. Our objective was to characterize the types of providers working with family physicians.

We used data from the American Board of Family Medicine examination application questionnaire in 2014. In each year family physicians were asked whether other health care providers worked at their primary practice site. If physicians applied for the examination multiple times, we kept their most recent response. We used descriptive statistics to characterize the data. Ethical approval was granted by the American Academy of Family Physicians Institutional Review Board.

This article was externally peer reviewed.

Submitted 22 July 2015; revised 21 October 2015; accepted 23 October 2015.

From the Robert Graham Center, Washington, DC (AB, PW, SP); and the American Board of Family Medicine, Lexington, KY (LP).

Funding: none.

Conflict of interest: none declared.

Corresponding author: Andrew Bazemore, MD, MPH, The Robert Graham Center, 1350 Connecticut Ave NW, Suite 201, Washington, DC 20036 (E-mail: abazemore@aafp.org).
Among a sample of 11,220 family physicians, over half $(52 \%)$ reported working with NPs and $39 \%$ with PAs. However, despite the oft-cited importance of behavioral health-primary care integration to achieving the triple aim, the reported prevalence of behavioral specialists $(21 \%)$ and psychiatrists $(12 \%)$ in family practice teams was far less. Pharmacists, social workers, midwives, and physical or occupational therapists were present in fewer than $20 \%$ of family physician practice teams (Figure 1).

Family physicians seem to be heeding calls to broaden primary care teams to better meet patient needs, though behavioral health integration remains limited in family medicine and other disciplines. The high percentages reporting work with NPs and PAs may be related to these providers' ability to more readily bill for clinical services. The presence of NPs and PAs in a majority of practices validates previously reported trends. Not surprisingly, physicians in small practices reported smaller teams; they will likely face additional hurdles to achieving team-based primary care. While these findings are encouraging and likely represent improved access and care for patients, the optimal balance of care teams for a given patient population remains unknown. Adapting lessons from pioneering and high-functioning teams, and taking advantage of broad federal investment in primary care extension and practice transformation, are critical to providing quality individual care while also improving population health and reducing costs. ${ }^{3-5}$ 
Figure 1. Family physicians recertifying in 2014 who reported working alongside a given profession. OT, occupational therapist; PT, physical therapist.

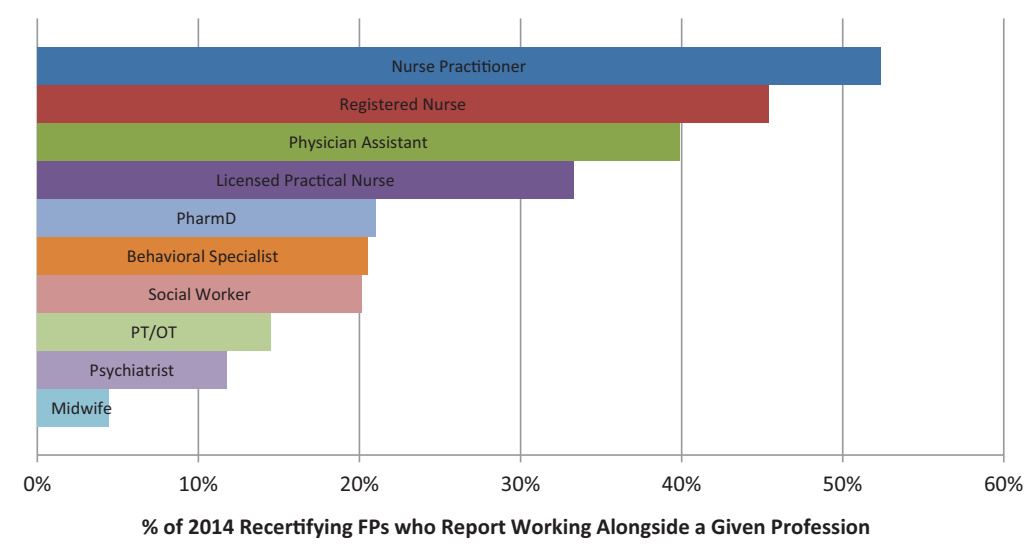

\section{References}

1. Taylor EF, Machta RM, Meyers DS, Genevro J, Peikes DN. Enhancing the primary care team to provide redesigned care: the roles of practice facilitators and care managers. Ann Fam Med 2013;11:80-3.

2. Peterson L, Blackburn B, Petterson S, Puffer J, Bazemore A, Phillips R. Which family physicians work routinely with nurse practitioners, physician assistants or certified nurse midwives. J Rural Health 2014;30: $227-34$.

3. Nutting PA, Crabtree BF, Miller WL, Stange KC, Stewart E, Jaén C. Transforming physician practices to patient-centered medical homes: lessons from the national demonstration project. Health Aff (Millwood) 2011;30:439-45.

4. Transforming Clinical Practices Initiative. Baltimore: Centers for Medicare \& Medicaid Services; June 2015. Available from: http://innovation.cms.gov/initiatives/ Transforming-Clinical-Practices/. Accessed November 11, 2015.

5. IMPaCT (Infrastructure for Maintaining Primary Care Transformation). Rockville, MD: Agency for Healthcare Research and Quality; September 2012. Available from: http://www.ahrq.gov/research/findings/ factsheets/primary/impactaw/index.html. Accessed June 29, 2015. 